\title{
Hyperglycemic Modification to Classical Two-Vessel Occlusion for Inducing Transient Cerebral Ischemia in Sprague-Dawley Rats
}

\author{
Wendy J. van der Spuy ${ }^{1,2,}$, Daniel J. Goosen ${ }^{3}$, Marius C. Bosman ${ }^{1}$ \\ ${ }^{1}$ University of Pretoria, Pretoria, South Africa \\ ${ }^{2}$ University of the Witwatersrand, Johannesburg, South Africa \\ ${ }^{3}$ La-Bio Research Laboratories, Pretoria, South Africa
}

${ }^{*}$ Corresponding author: Dr. Wendy J van der Spuy, School of Anatomical Sciences, University of the Witwatersrand, 7 York Road, Parktown, 2193, South Africa; Tel: +27 11717 2208; Fax: +27 86573 1066; Email: wendy.vanderspuy@wits.ac.za

\section{Received Date: April 09, 2015; Accepted Date: May 05, 2015; Published Date: May 07, 2015}

Citation: Wendy J. van der Spuy, et al. (2015) Hyperglycemic Modification to Classical Two-Vessel Occlusion for Inducing Transient Cerebral Ischemia in Sprague-Dawley Rats. J Neurophysiol Neurol Disord 1: 1-5.

\begin{abstract}
Cerebral ischemia is widely studied through the employment of experimental animal models. Incomplete global models such as two-vessel occlusion are relevant in the study of disease states which may attenuate cerebral ischemia. Hyperglycemia is known to worsen the consequences of ischemia but has not been exclusively employed. The two-vessel occlusion model, which is unsuccessful when employed in the absence of hypotension and/or hypoxia, is thus ideal for modification to a hyperglycemic model. We therefore describe an established technique for inducing hyperglycemic cerebral ischemia through modification of the two-vessel occlusion model as well as the procedure subsequently used to confirm cerebral injury. This method produces a larger degree of neural injury in males than in females, with estradiol levels negatively correlated to neural injury, confirming trends in research where estrogen is shown to be neuroprotective. Overall, this data is consistent with findings obtained by other groups, showing the neuroprotective nature of endogenous estradiol in rat models, with cyclic female animals sustaining less neural injury than age-matched male and acyclic female counterparts Furthermore, this technique proves to be simple, highly repeatable and cost effective. In conclusion, the hyperglycemic cerebral ischemia model developed as a modification to the two-vessel occlusion model (with exclusion of hypoxia and/or hypotension) proved successful for the study of cerebral ischemia.

Keywords: Hyperglycemia; Experimental ischemia; Sprague-Dawley, TTC
\end{abstract}

\section{Introduction}

A multitude of focal and global models for experimental cerebral ischemia are distinguished and employed in research facilities worldwide[1-3]. Various mechanisms of stroke induction are available; including focal and global models performed in either a permanent or transient manner[1]. The major advantages of incomplete global over focal ischemic models are that the length of ischemia is a great deal shorter and achievement of repeatability is more successful[4-6].

Incomplete global models, such as two-vessel occlusion (transient bilateral common carotid artery occlusion combined with systemic hypotension or hypoxia), are fairly simple to employ and achieve repeatability. This model is relevant in ischemia caused by disease states such as diabetes and atherosclerosis, as well as in traumatic brain injury[7].

(C)2013 The Authors. Published by the JScholar under the terms of the Creative Commons Attribution License http://creativecommons.org/licenses/ by $/ 3.0 /$, which permits unrestricted use, provided the original author and source are credited
Two-vessel occlusion without hypotension or hypoxia, however, is neither sufficient to bring cerebral blood flow down below the ischemic threshold, nor to upset the brain's energy state enough to produce quantifiable cell death[4-6]. Rats possess a posterior communicating artery and a complete circle of Willis[2], therefore posterior circulation will compensate for anterior occlusion up to a certain threshold. For this reason either blood flow or oxygenation of blood has to be reduced at the same time that the carotid arteries are occluded in order to produce quantifiable neural injury[4-6]. It is clearly understood that hyperglycemia (as in diabetes) intensifies the outcome of cerebral ischemia in both focal and global cerebral ischemic models[8,9]. Moderate pre-ischemic hyperglycemia enhances neuronal and glial injury and has been shown to significantly aggravate the blood-brain barrier and accentuate edema, thus worsening the consequences of transient forebrain ischemia, potentially through increasing cerebrovascular permeability by affecting endothelial integrity $[8,9]$. 
In this paper, we present a modified technique for two-vessel occlusion, with the inclusion of mild systemic hyperglycemia and the exclusion of hypotension and/or hypoxia. This technique is simple to employ, highly repeatable and ideal for laboratories where funding is limited.

\section{Materials and Methods}

Ketamine/Xylazine anesthesia is proven to cause acute hyperglycemia in fed but not fasted Sprague-Dawley rats, with glucose levels remaining elevated for approximately three hours post-anesthesia[10]. The classical two-vessel occlusion model performed in rats is accompanied by either hypoxia or hypotension to attenuate cerebral ischemia, by preventing collateral blood supply to the forebrain during the procedure[2,4-6]. To assess the effects of systemic hyperglycemia in exclusivity, a modified two-vessel occlusion model was employed, anesthetizing fed-state rats with a Ketamine/Xylazine combination, without inducing hypoxia or hypotension.

\section{Animal care}

Upon acquisition, the age-matched animals (24 males, 24 cyclic females and 24 acyclic females (ovariectomised two weeks prior)) were allowed to acclimatize for five days prior to the commencement of surgical procedures. They were maintained in a micro-barrier unit consisting of individually ventilated cages, at the laboratory animal facility of La-Bio Research (Tshwane University of Technology, Pretoria, South Africa). The physical size of the cages was in accordance with European standards and allowed for the animals to conduct their species specific behavior. The animal room temperature was maintained between $19-23^{\circ} \mathrm{C}$ with a humidity level of $45-75 \%$. A $12 \mathrm{~h}$ day/night cycle is a constant in the animal unit and light intensity is kept between 70-100Lux. The animals were provided with suitable food and water ad libitum. Food, water and bedding were autoclaved before use in the cages, as required for use in a micro-barrier unit.

All experimental procedures were carried out in strict accordance with the requirements of the South African National Standard (SANS 10386:2008) pertaining to the care and use of animals for scientific purposes. Ethical clearance was obtained from the University of Pretoria's Animal Use and Care Committee as well as the Tshwane University of Technology's Animal Research Ethics Committee.

\section{Induction of transient experimental cerebral is- chemia}

Fed-state animals were anaesthetized intraperitoneally (IP) with Ketamine/Xylazine (Ketamine $100 \mathrm{mg} / \mathrm{kg}$ IP and Xylazine $10 \mathrm{mg} / \mathrm{kg} \mathrm{IP}$ ) and temperature probes inserted rectally. Warming pads were used to maintain the animals' body temperature at $37^{\circ} \mathrm{C}\left( \pm 0.5^{\circ} \mathrm{C}\right)$. A tail prick was then performed to measure blood glucose levels in order to confirm hyperglycemia (>150mg/dl), using an Accu-Chek ${ }^{\circledast}$ Performa Nano blood glucose meter (Dischem, Pretoria, South Africa). Upon confirmation of hyperglycemia, induction of experimental cerebral ischemia was commenced in spontaneously breathing rats, with the aid of an operating microscope.

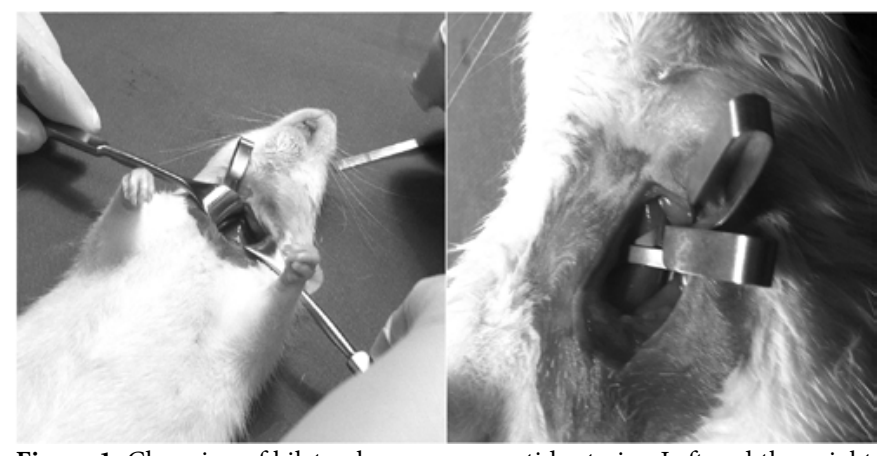

Figure 1: Clamping of bilateral common carotid arteries. Left and then right common carotid arteries were occluded with microsurgical vessel clips within a minute of each other and left in place for 15 minutes to induce cerebral ischemia. The incision was covered with dampened gauze to prevent tissue drying.

Bilateral common carotid arteries were exposed through a single midline neck incision and carefully dissected free from surrounding fascia and the adjacent vagus nerve. Left and then right arteries were occluded with microsurgical Schwarz Vessel Clips with slightly angled jaws (Surgical Tools Inc., Virginia, USA) within one minute of each other (Figure 1). The neck incision was covered with saline buffer-dampened gauze to prevent drying of tissues. Transient experimental cerebral ischemia was induced for a period of $15 \mathrm{~min}$ after which the vessel clips were removed and reperfusion allowed. Carotid arteries were inspected to ensure return of good pulsations before the neck incision was closed with a resorbable suture. Animals were monitored regularly for abnormal post-operative behaviour indicative of pain or discomfort. Monitored parameters included, but were not limited to, appetite, locomotive behaviour and respiratory pattern. Following assessment upon waking and subsequently, the administration of postoperative analgesics was not deemed necessary. Animals were allowed to survive for up to $48 \mathrm{~h}$ with free access to food and water. No animals were lost due to complications arising from surgical procedures.

\section{Determination of $17 \beta$-estradiol levels}

Blood was collected from each individual animal by cardiac puncture upon termination, for analysis at Ampath Pathology Laboratory Support Services (Pretoria, South Africa). At least $200 \mu \mathrm{l}$ of serum was required for $17 \beta$-oestradiol analysis by chemiluminescence method using a Beckman Coulter Uni$\mathrm{Cel}^{\circledR}$ DxI 800 Immunoassay System. Chemiluminescence technology employs the generation of electromagnetic radiation in the form of light by the release of energy from a chemical reaction. Values obtained were entered into the SAS ${ }^{\circledast}$ (Version 9.3) statistical program for further analysis.

\section{Confirmation of cerebral injury}

Whole brains were removed from each individual animal upon termination, for analysis of neural tissue injury. The simplest and most effective method of whole brain removal proved to be cutting the skull cap with scissors from each orbit, laterally to the rear of the skull and reflecting it forward (Figure 2). The brain could then be carefully scooped out upon severance of the medulla oblongata. Upon removal, the cerebellum and olfactory bulbs were carefully dissected off and discarded. 


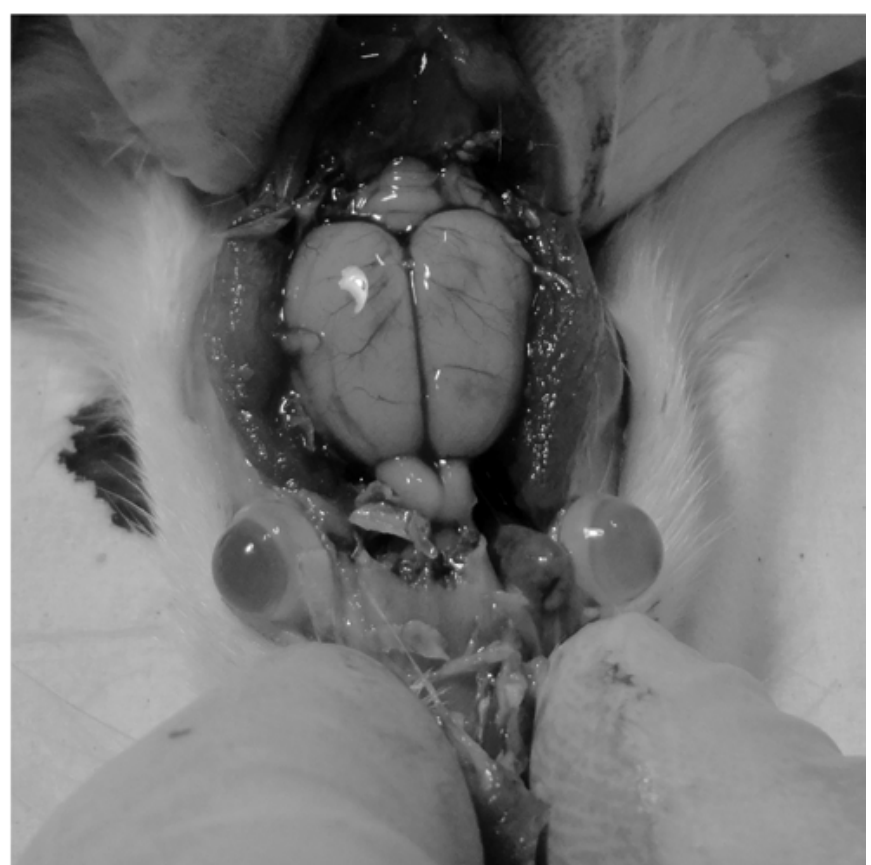

Figure 2: Skull cap removal. The skull cap was cut from each orbit, laterally to the rear and reflected forward. Whole brains were removed, cerebellum and olfactory bulbs dissected off for analysis of cerebral tissue.

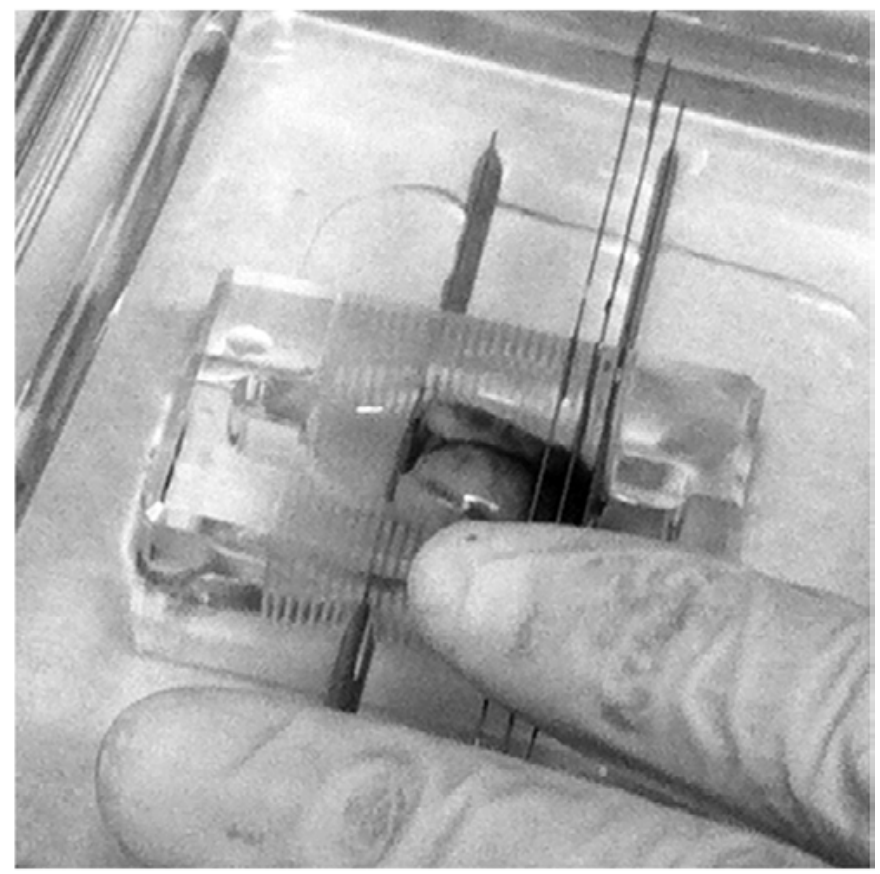

Figure 3: Coronal slices of cerebrum made using a rat brain matrix. To ensure evenly sliced sections, several blades were positioned in series in every second slot and a single slicing action was employed. Blades were removed individually and neural sections transferred directly to the staining container.

The cerebrum was then weighed before sectioning into $2 \mathrm{~mm}$ coronal sections (Figure 3) using an adult rat coronal brain matrix (Wirsam Scientific and Precision Equipment Pty Ltd., Johannesburg, South Africa) submerged in chilled $0.1 \mathrm{M}$ phosphate buffered saline (PBS). To quantify ischemic damage, sections were stained in a flat-bottomed, sealed container with $0.2 \%$ 2,3,5-Triphenyltetrazolium chloride (TTC) (SigmaAldrich ${ }^{\circledast}$, Kempton Park, South Africa) in $0.1 \mathrm{M} \mathrm{PBS}$ at a $\mathrm{pH}$ of 7.40 in a laboratory with temperature regulated at $19-23^{\circ} \mathrm{C}$. The period for staining was optimized at $3.5 \mathrm{~h}$ to ensure both clear demarcation of viable versus ischemic tissue and for pen- etration of the stain through a $2 \mathrm{~mm}$ section. During staining, the container was gently agitated every $5 \mathrm{~min}$ to ensure even distribution of stain throughout[11].

The TTC solution was then removed from the container and the sections washed in two changes of $0.1 \mathrm{M}$ PBS with duration of $1 \mathrm{~min}$ each. A solvent of 50:50 Ethanol/Dimethylsulfoxide (EtOH/DMSO)[12] was added to the container at $20 \mathrm{ml} / \mathrm{g}$ of Tissue[13] and allowed to extract the TTC formazan product from the tissue for $24 \mathrm{~h}$ in a dark cupboard. This period of extraction was determined sufficient to dissolve and redistribute the tissue formazan throughout the contents of the container in our laboratory. At the conclusion of the $24 \mathrm{~h}$ extraction, the container was briefly shaken and extract drawn out for absorbance measurement of each brain $[13,14]$. Six repeats per brain of $200 \mu \mathrm{l}$ per well in a 96well plate (10 times dilutions of extract $(20 \mu \mathrm{l})$ in EtOH/DMSO solvent $(180 \mu \mathrm{l}))$ were measured with a BioTek ${ }^{\circledR}$ Epoch Microplate Spectrophotometer (Analytical and Diagnostic Products, Roodepoort, South Africa) set at the optimal wavelength of $485 \mathrm{~nm}$. The percentage of neural injury was then calculated entering all repeat readings into the SAS ${ }^{\varpi}$ (Version 9.3) statistical program, to determine the neural tissue injury of each animal against each relevant control, using the following equation[13-15]:

$\%$ Tissue Injury $=100 x\left[1-\left(\right.\right.$ Absorbance $_{\text {Injury }} /$ Absorbance $\left._{\text {Control }}\right)$

\section{Results}

Experimental cerebral ischemia was successfully induced utilizing a hyperglycemic two- vessel occlusion model. The $17 \beta$-estradiol level was measured from blood plasma and neural tissue injury was measured from the whole brains of individual animals at $0 \mathrm{~h}$ (control) $2 \mathrm{~h}, 24 \mathrm{~h}$ and $48 \mathrm{~h}$ post-reperfusion.

\section{Neural tissue injury was higher in males than cy- clic or acyclic females}

Neural Tissue Injury (NTI) was evident in all experimental animals when compared to group-matched controls. Statistical analysis showed variability within the neural tissue injury model to be $63 \%$ and the p-value obtained for the model was $<0.0001$ with a confidence level of $95 \%$. Subsequent to induction of cerebral ischemia, neural tissue in males progressively deteriorated from $2 \mathrm{~h}$ to $48 \mathrm{~h}$ post-reperfusion, yielding the highest levels of neural tissue injury amongst the groups. The neural tissue of cyclic females presented the highest peak of neural injury at $2 \mathrm{~h}$ post-reperfusion, and regeneration variables were apparent at $24 \mathrm{~h}$, with oestrogen curbing the peak in inflammation. Acyclic females on the other hand presented with the highest level of neural injury at $24 \mathrm{~h}$, due to the inability to suppress necrosis and initiate recovery. Overall, across all time intervals, cyclic females presented significantly less neural tissue injury than males and acyclic females. In their groups, it was found that male $(\mathrm{NTI}=23.897 \%)$ rats displayed significantly more neural tissue injury than acyclic females $(\mathrm{NTI}=13.466 \%)$ who also in turn displayed significantly more neural tissue injury than cyclic females (NTI $=9.217 \%$ ) (Figure 4). Previously, neural tissue injury of this subset of animals 
Neural Tissue Injury



Figure 4: Percentage neural tissue injury per group for males and cyclic and acyclic females. Absorbance values per experimental animal was used to calculate neural tissue injury against absorbance values of animals allocated as controls to each group. Standard error was calculated to be $\pm 0.619 \%$. Stars indicate significance, males with significantly higher neural tissue injury than both female groups, and acyclic females with significantly higher neural tissue injury than the cyclic female group.

was correlated to alterations in platelet ultrastructure at specific time points to establish that neural injury and the fluctuation of inflammation associated with such injury is mirrored by changes in platelet morphology[15].

\section{Serum estradiol levels increased after ischemic in- sult}

$17 \beta$-estradiol is a known neuroprotective agent and determination of endogenous estradiol levels allows for further substantiation of the effectiveness of the technique, as literature shows consistent data that female animals display less neural injury than male counterparts[16-19]. In the analysis of $17 \beta$-estradiol levels, it was confirmed that cyclic females (169.833pmol/l) had significantly higher serum levels of female reproductive hormone than both males $(68.667 \mathrm{pmol} / \mathrm{l})$ and acyclic females (56.333pmol/l). Subsequent to cerebral ischaemia/reperfusion, it was found that circulating estradiol was upregulated across all groups at $2 \mathrm{~h}$ post-reperfusion where initial ischemic injury was apparent, though to a lesser extent in males and acyclic females than in cyclic females. The expression of neural estrogen receptors is known to be upregulated subsequent to cerebral ischemia[19-21]. Analysis of the correlation between neural tissue injury and estradiol levels revealed a significant negative correlation between the two, confirming that estrogen is neuroprotective as higher levels thereof gave rise to neural injury of lesser degree.

\section{Discussion}

From the neural tissue injury results, it can be deduced that subsequent to cerebral ischemia cyclic female neural tissue presents the lowest overall loss of integrity with high estradiol levels curbing inflammation early on[15] and initiating recovery by stalling apoptosis[22,23]. The neural tissue of males is shown to deteriorate significantly in the absence of adequate estradiol due to an inability to curb the inflammatory response and suppress apoptosis. Acyclic females, also with low estradiol levels, display a smaller degree of injury to males in this study. Though the lack of estrogen in acyclic females definitely lessens neuroprotection, there appears to be some inherent degree of protection, at least two weeks subsequent to bilateral ovariectomy, from the insult of mild cerebral ischemic injury when compared to males; possibly due to an inherent state of inflammation termed thrombotic preparedness[15,24,25] which may lessen the initial inflammatory shock of ischemic injury to the neural tissue.

Overall, this data is consistent with findings obtained by other groups, showing the neuroprotective nature of endogenous estradiol in rat models, with cyclic female animals sustaining less neural injury than age-matched male and acyclic female counterparts[16-19]. In conclusion, the hyperglycemic cerebral ischemia model developed as a modification to the two-vessel occlusion model (with exclusion of hypoxia and/or hypotension) proved successful for the study of cerebral ischemia as it produced quantifiable and repeatable neural injury.

\section{Acknowledgements}

The authors declare no conflict of interest. The authors wish to thank the staff of La-Bio Research Laboratory for their professional assistance during the study. Finally, the authors wish to express gratitude to the Department of Anatomy at the University of Pretoria for the funding of this postgraduate stroke research. Each author contributed either to the conception, design and execution of the reported technique (WJS, DJG, MCB), drafting (WJS) and/or finalization of the manuscript (WJS, MCB).

\section{References}

1) Braeuninger S, Kleinschnitz C (2009) Rodent models of focal cerebral ischemia: procedural pitfalls and translational problems. Exp Transl Stroke Med 1:8.

2) Hoyte LC, Buchan AM (2009) Animal models of stroke. In: Hof PR, Mobbs CV (Eds), Handbook of the Neuroscience of Aging. Elsevier Inc., Italy, 575-582.

3) Traystman RJ (2003) Animal models of focal and global cerebral ischemia. ILAR J 44: 85-95.

4) Eklöf B, Siesjö BK (1972) The effect of bilateral carotid artery ligation upon the blood flow and energy state of the rat brain. Acta Physiol Scand 86:155-165.

5) klöf B, Siesjö BK (1973) Cerebral blood flow in ischemia caused by carotid artery ligation in the rat. Acta Physiol Scand 87:69-77.

6) McBean DE, Kelly PA (1998) Rodent models of global cerebral ischemia: a comparison of two-vessel occlusion and fourvessel occlusion. Gen Pharmacol 30:431-434.

7) Ginsberg MD, Busto R (1989) Rodent models of cerebral ischemia. Stroke 20:1627-1642.

8) Dietrich WD, Alonso O, Busto R (1993) Moderate hyperglycemia worsens acute blood-brain barrier injury after forebrain ischemia in rats. Stroke 24:111-116.

9) Pulsinelli WA, Waldman S, Rawlinson D, Plum F (1982) Moderate hyperglycemia augments ischemic brain damage: a neuropathological study in the rat. Neurology 32:12391246. 
10) Saha JK, Xia J, Grondin JM, Engle SK, Jakubowski JA (2005) Acute hyperglycemia induced by ketamine/xylazine anesthesia in rats: mechanisms and implications for preclinical models. Exp Biol Med (Maywood) 230:777-784.

11) Joshi CN, Jain SK, Murthy PS (2004) An optimised triphenyltetrazolium chloride method for identification of cerebral infarcts. Brain Res Brain Res Protoc 13:11-17.

12) Sladowski D, Steer SJ, Clothier RH, Balls M (1993) An improved MTT assay. J Immunol Methods 157:203-207.

13) Xue QS, Yu BW, Wang ZJ, Chen HZ (2004) Effects of ketamine, midazolam, thiopental, and propofol on brain ischemia injury in rat cerebral cortical slices. Acta Pharmacol Sin 25:115-120.

14) Preston E, Webster J (2000) Spectrophotometric measurement of experimental brain injury. Journal of Neuroscience Methods 94:187-192.

15) van der Spuy WJ, Pretorius E (2013) A place for ultrastructural analysis of platelets in cerebral ischemic research. Microscopy Research and Technique 76:795-802.

16) Liao S, Chen W, Kuo J, Chen C (2001) Association of serum estrogen level and ischemic neuroprotection in female rats. Neurosci Lett 297:159-162.

17) McCullough LD, Hurn PD (2003) Estrogen and ischemic neuroprotection: an integrated view. Trends Endocrinol Metab 14:228-235.

18) Selvamani A, Sohrabji F (2010) Reproductive age modulates the impact of focal ischemia on the forebrain as well as the effects of estrogen treatment in female rats. Neurobiol Aging 31:1618-1628.

19) Suzuki S, Brown CM, Wise PM (2009) Neuroprotective effects of estrogens following ischemic stroke. Front Neuroendocrinol 30:201-211.

20) Dubal DB, Zhu H, Yu J, Rau SW, Shughrue PJ, et al. (2001) Estrogen receptor alpha, not beta, is a critical link in estradiolmediated protection against brain injury. Proc Natl Acad Sci U S A 98:1952-1957.

21) Suzuki S, Brown CM, Dela Cruz CD, Yang E, Bridwell DA, et al. (2007) Timing of estrogen therapy after ovariectomy dictates the efficacy of its neuroprotective and antiinflammatory actions. Proc Natl Acad Sci U S A 104:6013-6018.

22) Drača $S$ (2009) Are female sex steroids neuroprotective in experimental stroke. Med Hypotheses 73:1051-1052.

23) Manthey D, Behl C (2006) From structural biochemistry to expression profiling: neuroprotective activities of estrogen. Neuroscience 138:845-50.

24) Gharacholou SM, Becker RC (2009) Hemostasis and thrombosis in older adults. Journal of Thrombosis and Thrombolysis 27:249-251.

25) Pretorius E, Oberholzer HM, van der Spuy WJ, Meiring JH (2010) Age-related changes in fibrin networks and platelets of individuals over 75: a scanning electron microscopy study showing "thrombotic preparedness". J Thromb Thrombolysis 29:271-275.
Submit your manuscript to a JScholar journal and benefit from:

ฯ Convenient online submission

ฯ Rigorous peer review

I Immediate publication on acceptance

q Open access: articles freely available online

ब High visibility within the field

ब Better discount for your subsequent articles

Submit your manuscript at http://www.jscholaronline.org/submit-manuscript.php 